\title{
Discours
}

Revue de linguistique, psycholinguistique et

informatique. A journal of linguistics, psycholinguistics and computational linguistics

$12 \mid 2013$

Varia

\section{Length Matters: Informational Load in Ambiguity Resolution}

\author{
Barbara Hemforth, Saveria Colonna, Caterina Petrone and Mariapaola
} D'Imperio

\section{OpenEdition}

\section{Journals}

Electronic version

URL: http://journals.openedition.org/discours/8780

DOI: $10.4000 /$ discours. 8780

ISSN: $1963-1723$

Publisher:

Laboratoire LATTICE, Presses universitaires de Caen

Electronic reference

Barbara Hemforth, Saveria Colonna, Caterina Petrone and Mariapaola D'Imperio, « Length Matters: Informational Load in Ambiguity Resolution », Discours [Online], 12 | 2013, Online since 10 July 2013, connection on 01 May 2019. URL : http://journals.openedition.org/discours/8780 ; DOI : 10.4000/ discours. 8780

Discours est mis à disposition selon les termes de la licence Creative Commons Attribution - Pas d'Utilisation Commerciale - Pas de Modification 4.0 International. 

Revue de linguistique, psycholinguistique et informatique

\title{
Length Matters: Informational Load in Ambiguity Resolution
}

\author{
Barbara Hemforth \\ Laboratoire de Linguistique formelle, UMR 7110 \\ CNRS - Université Paris VII-Diderot \\ Saveria Colonna \\ Laboratoire Structures formelles du langage, UMR 7023 \\ CNRS - Université Paris VIII-Vincennes \\ Caterina Petrone \\ Laboratoire Parole et langage, UMR 6057 \\ CNRS - Université d'Aix-en-Provence \\ Mariapaola D'Imperio \\ Laboratoire Parole et langage, UMR 6057 \\ CNRS - Université d'Aix-en-Provence et Institut universitaire de France
}





\title{
Length Matters: Informational Load in Ambiguity Resolution
}

\author{
Barbara Hemforth \\ Laboratoire de Linguistique formelle, UMR 7110 \\ CNRS - Université Paris VII-Diderot

\section{Saveria Colonna} \\ Laboratoire Structures formelles du langage, UMR 7023 \\ CNRS - Université Paris VIII-Vincennes

\section{Caterina Petrone} \\ Laboratoire Parole et langage, UMR 6057 \\ CNRS - Université d'Aix-en-Provence

\section{Mariapaola D'Imperio} \\ Laboratoire Parole et langage, UMR 6057 \\ CNRS - Université d'Aix-en-Provence et Institut universitaire de France
}

In this paper, we will compare prosodic and pragmatic approaches to the role of constituent length in attachment ambiguities. Lengthening a constituent affects its informativity: longer constituents are usually less predictable (Levy \& Florian, 2007) and demand a higher processing load than shorter ones (Almor, 1999). Following neo-Gricean accounts (Levinson, 1987 and 1991), increased informational load needs to be justified. This justification is achieved more easily when the long constituent conveys new information and when it relates to central elements of the utterance. Informational load is, however, not a simple question of length in numbers of characters or syllables but more likely a question of amount of information. In three off-line experiments using a cloze task, we will compare the effect of lengthening ambiguous prepositional phrases as in $[1 \mathrm{a} / \mathrm{b} / \mathrm{c}]$ either by lengthening a city name or by adding information about the city. We will show that only lengthening by adding information increases attachment to a more central element of the utterance. These results will be discussed based on prosodic and pragmatic factors explaining the role of constituent length for attachment ambiguities.

[1] Peter met the doctor of the lawyer from a. Apt. / b. Aix-en-Provence / c. the beautiful city of Apt.

Keywords: implicit prosody, prepositional phrases attachment, length effects, pragmatics

Dans cet article, nous comparons une approche prosodique avec une approche pragmatique pour rendre compte des effets de la longueur des constituants dans les ambigüités d'attachement. Augmenter la longueur d'un constituant a des conséquences sur l'information qu'il véhicule: plus un constituant est long et moins il est prédictible (Levy et Florian, 2007) et plus son coût de traitement augmente (Almor, 1999). Suivant les principes néo-gricéens (Levinson, 1987 et 1991), augmenter le poids informationnel doit être justifié. Cette justification est plus facilement satisfaite lorsqu'un constituant long véhicule une information nouvelle et/ou qui se rapporte aux éléments centraux de l'énoncé. Le coût informationnel ne se résume cependant pas à une simple question de 


\begin{abstract}
longueur en termes de nombre de caractères ou de syllabes mais plus probablement à la quantité d'information véhiculée. Dans trois questionnaires, nous comparons l'effet de l'augmentation de la longueur d'un syntagme prépositionnel ambigu comme dans [1a/b/c], soit en allongeant le nom de la ville, soit en ajoutant de l'information au sujet de la ville. Nous observons que seul l'ajout d'information augmente la proportion d'attachement du syntagme prépositionnel au constituant central de l'énoncé. Ces résultats sont discutés à la lumière des facteurs prosodiques et pragmatiques qui peuvent rendre compte des effets de longueur observés sur les préférences d'attachement.

[1] Pierre a rencontré le docteur de l'avocat a. d'Apt. / b. d'Aix-en-Provence / c. de la magnifique ville d'Apt.
\end{abstract}

Mots clés: prosodie implicite, attachement des syntagmes prépositionnels, effets de longueur, pragmatique

\title{
1. Length effects in language processing
}

The role of the length of a constituent has been discussed in great detail in the recent literature on word ordering phenomena and on attachment ambiguities. The general pattern to be found is that longer constituents usually occur later in the sentence as can be seen in the citation [2a] which follows the non-canonical PP (prepositional phrase) $<$ NP (noun phrase) order due to the fact that the object NP is more than six times longer than the PP. The canonical order in [2b] seems intuitively harder to process (cited by Arnold et al., 2000: 32, from Hyams \& Wexler, 1993). In case of ambiguity, longer constituents tend to be attached higher in the phrase marker of the sentence than short constituents [3a-b]; (see for example Pynte \& Colonna, 2000; Hemforth et al., submitted). The length of a constituent also tends to correlate positively with newness: given constituents tend to be shorter than new ones (Bard \& Aylett, 1999; Bard et al., 2000).

[2] a. The Informativeness account shares $\left[_{\mathrm{PP}}\right.$ with the processing account $]\left[_{\mathrm{NP}}\right.$ the claim that a subjectless sentence is not a grammatical option for the child, and that the omission is due to some aspect of performance].

b. The Informativeness account shares $\left[_{\mathrm{NP}}\right.$ the claim that a subjectless sentence is not a grammatical option for the child, and that the omission is due to some aspect of performance] $\left[_{\mathrm{PP}}\right.$ with the processing account].

[3] a. The doctor met the son of the colonel who died.

b. The doctor met the son of the colonel who tragically died of a stroke.

In this paper, we are mostly interested in the role of constituent size for modifier attachment ambiguities. Both the size of a potential host (Thornton et al., 2000; Colonna \& Pynte, 200I) as well as the size of the modifier itself (Fernández, 2003; Watson \& Gibson, 2004; Hemforth et al., submitted) play a role here. In the following, we will present prosodic and pragmatic approaches to length effects in modifier attachment before presenting three off-line experiments on PP-attachment ambiguities. We will show that adding information plays a crucial role in attachment preferences. 


\section{Implicit prosody}

In a seminal paper, Janet D. Fodor (2002) stated that "psycholinguistics cannot escape prosody". In her so-called Same Size Sister (SSS) principle ("Find a sister of your own size", Fodor, 1998: 302), she claims that syntactic analysis and in particular structural ambiguity resolution are affected by metrical aspects of prosody. The central point here is the direction of influence: Fodor assumes that prosodic contours are computed very quickly and are used to inform syntactic processes, thus directly influencing syntactic phrasing decisions. According to the Implicit Prosody Hypothesis (IPH), Fodor further assumes that this prosodic explanation can also be applied to silent reading since readers automatically compute a prosodic representation of the sentence even while reading silently. Therefore, even in reading experiments, psycholinguistics cannot escape prosody because it always plays an important role in informing syntactic analysis.

A striking example of the influence of metrics is the following Japanese construction $[4 a-b]$, which is ambiguous between the reading "sister of an extremely kind student" and "extremely kind sister of a student". Although incremental processing might predict a preference to group kyokutanni shinsetsu gakusei-no ("extremely kind student") as in [4a], participants actually prefer the second interpretation which allows two prosodic units of roughly the same size kyokutanni shinsetsu and gakusei-no imooto as in [4b].

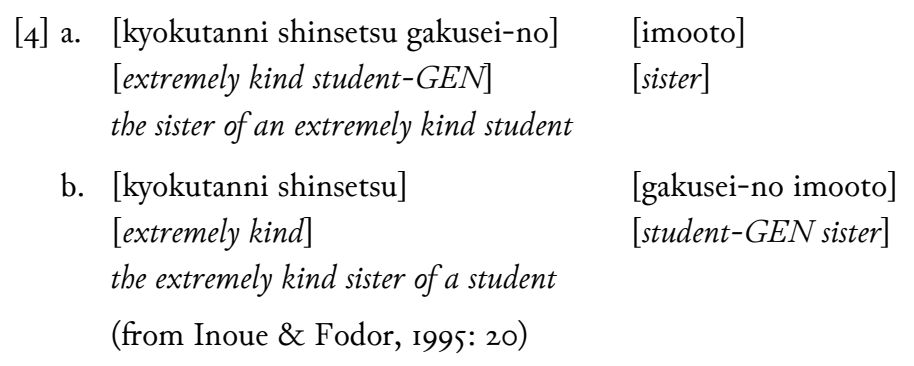

This hypothesis has been specifically tested on ambiguous modifiers such as relative clauses (RCs): the hypothesis derived from the SSS hypothesis is that these modifiers tend to attach to a head of similar prosodic size. For two-site ambiguities of the type $\left[\mathrm{NP}_{\mathrm{I}}-\mathrm{of}-\mathrm{NP}_{2}-\mathrm{RC}\right]$ as in $[3 \mathrm{a}-\mathrm{b}]$, this means that a long RC is preferentially attached to NPI since NPI includes $\mathrm{NP}_{2}$ and is therefore longer than $\mathrm{NP}_{2}$ only. Short RCs on the other hand are preferentially attached to the shorter $\mathrm{NP}_{2}$ which is of similar prosodic heaviness.

The role of constituent size for attachment ambiguities has since been demonstrated for many different languages such as English, Spanish, Croatian, French, and German (among many others: Fodor, 1998 and 2002; Pynte \& Colonna, 2000; Abeillé et al., 200I; Carlson et al., 2001; Bradley et al., 2003; Fernández, 2003; Jun, 2003; Watson \& Gibson, 2004; Hemforth et al., submitted). 
One of the critical points raised very often in comments on the on-line effect of the length of prosodic units is that listeners or readers cannot really know about the length of an upcoming constituent before they have actually heard all of it. Sentence processing is usually taken to be a highly incremental process where words are integrated into the current syntactic and semantic representation of the sentence as soon as possible (e.g., Frazier, 1987; Hemforth et al., 1993). This means that as soon as the left boundary of a constituent is recognized, integration starts. However, at this point the unknown length of a constituent can hardly influence its integration.

However, it is well known by now that listeners can profit from information in the signal telling them whether they are about to hear a long or a short sentence. In addition to explicit breaks, longer sentences tend to start with higher frequency and with shorter syllable durations (Muckel Pappert et al., 2004), so that listeners can infer length aspects even at the beginning of the sentence (or of the RC, for instance).

Of course, this is not true for implicit prosody in reading. Effects of metrical structure on attachment processes in reading might even compromise the idea of fully incremental syntactic structuring, as Pynte (2006) notes. He shows for French that the length of constituents in the syntactic context of an ambiguous construction influences attachment preferences in reading as well as in listening. The most interesting of Pynte's three experiments for our purposes is Experiment 2, a segment-by-segment self-paced reading experiment, since it directly taps into the question of implicit prosody in reading. Presentation of the sentences was segmented as indicated by the markings in examples [ $5 \mathrm{a}-\mathrm{d}]$ and participants had to judge sentence acceptability at the end of the sentence. Pynte manipulated two experimental factors: PP-attachment was disambiguated by the preposition $d e$ vs. $d u$. The preposition $d e$ forces a noun modifier reading while $d u$ forces verb attachment. The second factor concerned the length of the segments surrounding the critical region (in capitals in examples [5a-d] for expository purposes), which were either short as in [ $5 \mathrm{~b}, \mathrm{~d}]$ or long as in [ $5 \mathrm{a}, \mathrm{c}]$. The critical unit always comprised the direct object NP and the following PP. Assuming that the segmenting of the sentences enforces prosodic units, long segments correspond to a balanced prosodic structure while short surrounding segments break the balance. Pynte suggests that, if a sentence is prosodically balanced as in [5a] and $[5 c]$, the attachment preference is based on a general bias for verb attachment. In the self-paced experiment (Experiment 2), verb attached PPs (cette cbaine $d u$ vélo) were actually judged acceptable faster than NP-attached PPs (cette chainne de vélo) in the balanced conditions. If, however, the constituents in the surrounding syntactic context were short as in $[5 \mathrm{~b}]$ and $[5 \mathrm{~d}]$, a long "prosodic" unit was taken to be informative in that it imposed a corresponding semantic unit: cette chaîne de vélo was judged acceptable slightly faster in this case. Note that this result is also in line with predictions from the Rational Speaker Hypothesis (Clifton et al., 2002; Clifton et al., 2006). 
[5] a. Il avait enlevé / CETTE CHÂ̂NE DU véLo / et l'avait posée / sur l'établi.

He had removed this chain from the bicycle and had put it on the workbench.

b. Il enlève / CETTE CHAÎNE DU VÉLO / et la pose / sur l'établi.

He removes this chain from the bicycle and puts it on the workbench.

c. Il avait enlevé / CETTE CHAÎNE DE vÉLO / et l'avait posée / sur l'établi. He had removed this bicycle chain and had put it on the workbench.

d. Il enlève / CETTE CHAÎNE DE VÉLo / et la pose / sur l'établi.

He removes this bicycle chain and puts it on the workbench.

Interestingly, the expected effect of segment length did not show up in reading times on the critical region itself nor on following regions but only late for acceptability judgement times. Pynte suggests that the late effect of prosodic balancing in judgement times is a consequence of a retroactive influence of prosody on syntactic attachment. He suggests that the global prosodic phrasing of a sentence is taken into account for attachment. As a consequence syntactic attachment during sentence processing can only be preliminary and may be adjusted by the end of the sentence to allow for optimal prosodic phrasing. It is actually true that in most experiments length effects are measured at the end of the sentence so that they may actually be the result of a retroactive influence of prosody.

Further evidence that length may have an influence even in the absence of semantic and pragmatic differences comes from a series of experiments by Wijnen (2004). He presented participants with Dutch Jabberwocky RC-attachment constructions such as [6a-d] where all content words were replaced by phonologically legal short or long non-words (Experiment I in Wijnen, 2004). All RCs were short passive constructions (either adjectival with was or verbal with werd) fully ambiguous with respect to the attachment site. The participants' task was to decide whether the RC modified Ni or N2.

[6] long-short: a. de $\left[{ }_{\mathrm{N}_{1}}\right.$ kalambulo] van de $\left[_{\mathrm{N}_{2}}\right.$ fup] $\left[_{\mathrm{RC}}\right.$ die verstritst was] long-long: b. de $\left[_{\mathrm{N}_{1}}\right.$ knilpatsiera] van de $\left[_{\mathrm{N}_{2}}\right.$ astrublankor $]\left[_{\mathrm{RC}}\right.$ die verdrimd werd] short-long: c. de $\left[_{\mathrm{N}_{1}}\right.$ slos] van de $\left[_{\mathrm{N}_{2}}\right.$ prefrastiaan] $\left[_{\mathrm{RC}}\right.$ die bedrept was] short-short: d. de $\left[_{\mathrm{N}_{1}}\right.$ vrink] van de $\left[_{\mathrm{N}_{2}}\right.$ orcht] $\left[_{\mathrm{RC}}\right.$ die betrind werd] the N1 of N2 who VERB / ADJECTIVE was

Following the IPH, participants should have a tendency to insert a break after a long noun so that $\mathrm{N}_{2}$ should be grouped with the $\mathrm{RC}$ in $[6 \mathrm{a}, \mathrm{d}]$ whereas local attachment should be hindered by a break following $\mathrm{N}_{2}$ in [6b, c]. Off-line interpretation data are consistent with this hypothesis. Note, however, that the data on Jabberwocky seem to contradict results from an on-line eye movement experiment for French presented by Colonna and Pynte (200I) who report a preference for local attachment when adding an adjective to N2. Colonna and Pynte investigated attachment preferences for long RCs as in [7a-d]. They found shorter fixation times when the RC was forced to attach to the modified host. 
[7] a. Il connaît la fille des élégants Français qui entre dans le restaurant. He knows the daughter of the elegant French people who enters the restaurant.

b. Il connaît les élégantes filles du Français qui entrent dans le restaurant. He knows the elegant daughters of the Frenchman who enter the restaurant.

c. Il connait les filles de l'élégant Français qui entre dans le restaurant. He knows the daughters of the elegant Frenchman who enters the restaurant.

d. Il connait l'élégante fille des Français qui entrent dans le restaurant. He knows the elegant daughter of the French people who enter the restaurant.

Apparently, length does affect attachment preferences for semantically empty constructions (such as Jabberwocky) but not in the same way as adding words does. Adding content may actually increase the salience of the potential host, making it more accessible as an antecedent for the relative pronoun. This can explain the difference between Colonna and Pynte's data and the Jabberwocky data. The informational status of the hosts can only be of importance when the linguistic material encourages interpretation. Wijnen's experiments are moreover not conclusive with respect to effects of the length of the modifier itself. With longer RCs (Experiment 2 in Wijnen, 2004), he actually loses the predicted effects.

\section{The role of informational load}

Length effects in many experiments are, however, also compatible with an explanation based on pragmatic principles. In almost all the published experiments we are aware of, lengthening a modifier meant adding at least one, often several content words. Thus, the longer modifier always contained more and more detailed information. This means that processing the longer modifier is more costly from a semantic/ pragmatic standpoint. We may thus propose a principle which is based on the assumption that the informational load of a linguistic expression plays a functional role in processing (as e.g., in Almor, 1999).

Almor (1999) studied the role of informational load for anaphoric expressions. He defined informational load as a function expressing "the constraints on the simultaneous storage and processing of information in verbal working memory" (Almor, 1999: 750). For anaphoric expressions, Almor proposes that the pragmatic principle underlying the Informational Load Hypothesis (ILH) is the following: "The informational load of an anaphor with respect to a given antecedent should have a functional justification in either aiding the identification of the antecedent, adding new information about it, or both" (Almor, 1999: 750). More generally, this means that more and more detailed information has to be justified, or in other words, since cognitive processing effort has to be allocated to interpreting more information, that this effort has to be spent reasonably. Attaching the modifier to one of the possible hosts means, in the examples discussed so far, either adding information about a direct argument of the main predicate or about a modifier of this argument. 
The Principle of Relativized Relevance in [8] (Frazier, 1990; Frazier \& Clifton, 1996) predicts a general preference for modifying direct arguments. Combining Relativized Relevance with Almor's ILH, we can predict that the more informative a modifier, the more it will be likely to be related to the main assertion of the sentence. In the constructions investigated in this paper, this means that the more informative a modifier, the more likely it will be to show a preference for attaching to NI.

[8] Relativized Relevance

Other things being equal, e.g., all interpretations are grammatical, informative and appropriate to discourse, preferentially construe a phrase as being relevant to the main assertion of the sentence.

(Frazier, 1990: 321)

The role of informational load can also easily be phrased in neo-Gricean terms. Levinson's (1987; 199I) pragmatic theory of anaphoric reference proposes a series of principles, two of which are central to our line of argumentation, the I-principle and the M-principle.

- I-principle: Do not say more than is required.

- M-principle: Do not use a marked expression without reason.

It is highly reasonable to assume that more information is required for more central elements of the utterance whereas less information is needed for more peripheral elements such as modifiers of central elements. Longer expressions are marked since they violate any principle of economy and should be used for a reason, which will, again, provide information for central elements of the utterance.

Another informativity-based explanation for higher numbers of non-local attachments of long constituents can be derived from Quirk et al.'s (1985) principle of end weight. Quirk et al. define the tendency to place more important information or information with more content late as end weight, a constraint which is considered to be linked to end focus. Niv (1992) similarly proposed a principle of increasing order of information volume, which is consistent with this idea. A possible example for the role of end weight would be the high/low attachment ambiguity in [9a] and [9c]. Recency-based attachment principles (e.g., late closure, Frazier \& Fodor, 1978) predict a syntactic preference for local attachment of "yesterday" so that both, [9a] as well as [9c] result in a garden path due to the mismatch in the tense of the subordinate clause and the temporal adverbial. [9c] does, however, seem to be much easier to process than [9a]. Niv (1992) suggests that the reason why the longer constituent in [9c] can be attached high much more easily than the short one in [9a] is that the position of the adverbial clause is justified independently of its attachment. The short adverbial in [9a] could easily be realized adjacent to the main clause it modifies [9b]. This is however much less felicitous for the long adverbial clause [9d]. Longer constituents can thus more easily attach non-locally since length, or amount of informativity, justifies their position. 
[9] a. Tom said Bill will die yesterday.

b. Tom said yesterday that Bill will die.

c. Tom said Bill will die when he came home yesterday.

d. Tom said when he came home yesterday that Bill will die.

Corpus data on the Penn Treebank corroborate these predictions (Niv, 1992): longer adverbials occur after verbal arguments reliably more often than short adverbials. Evidently, there is a prosodic explanation for these data as well. A prosodic break is much more likely before the long [9c] than before the short constituent [9a]. The data provided so far, however, do not distinguish between prosodic and information based approaches. In order to shed light on this question, we need to vary length and informativity independently.

We ran a series of three questionnaire studies in French and German where we either increased length only by adding syllables to the modifier or by adding content words. Contrary to most studies in the literature, we did not investigate $\mathrm{RC}$-attachment ambiguities as in [Ioa] but PP-attachment ambiguities as in sentence [Iob]. The major reason for this choice was the fact that RCs are often claimed to have a special status within the sentence structure which is not necessarily the case for PPs (e.g., Construal Theory: Frazier \& Clifton, 1996; Attachment-Binding Dualism [ABD] ' 1 : Hemforth et al., zoooa and b). Frazier and Clifton (1996) claim that RCs are associated with a thematic domain in a first parse and only attached later based on a variety of semantic, pragmatic, and possibly prosodic constraints. The general prediction for PPs is that if they are in a position where they can be integrated as directly relating to the main assertion of the sentence, then they are attached immediately.

Hemforth et al. (2000a and b; Konieczny \& Hemforth, 2000) insist on the fact that RC-attachment includes a syntactic as well as an anaphoric component and is thus influenced by discourse related as well as syntactic factors. PPs, on the other hand, only follow syntactic attachment preference. Accordingly, while RC-attachment is predicted to vary easily depending on a variety of parameters, a systematic preference for low attachment is predicted for PPs. Hemforth et al. (2000a) provide clear evidence for a high attachment preference for RCs like [Ioa] and a low attachment preference for corresponding PPs such as [iob].

[ı] a. Der Student des Professors, der in dem neuen Labor war, las die Ergebnisse. The student of the professor who was in the new lab read the results.

b. Der Student des Professors in dem neuen Labor las die Ergebnisse. The student of the professor in the new lab read the results.

1. In the ABD model, only RCs whose attachment is assumed to be based on syntactic as well as anaphoric processes (due to the relative pronoun) are considered to be influenced by non-syntactic factors even in early steps of the analysis. 
Neither Construal, nor ABD explicitly predict any length effect for PPs whereas a length effect is clearly predicted by the SSS principle as well as by the ILH for RCs as well as for PPs.

\section{Experiment 1}

We conducted our first experiment in French. Here we compared PPs with invented city names and PPs with real city names. We chose the real city names from a list of all existing cities in France with more than 30,000 inhabitants. Both were presented in three length conditions $[11 \mathrm{a} / \mathrm{b} / \mathrm{c}],[12 \mathrm{a} / \mathrm{b} / \mathrm{c}],[13 \mathrm{a} / \mathrm{b} / \mathrm{c}]$ and $[14 \mathrm{a} / \mathrm{b} / \mathrm{c}]$ : short PP-object (2 syllables for invented names, I syllable for real names), long PP-object ( 5 syllables for invented names, 3.I on average syllables for real names), and composed PP-object ( 5 syllables for invented names, 3.9 syllables on average for real names). No content words were added to increase length. The complex NPs appeared in subject ([II] and [13]) or in object ([I2] and [14]) position. We controlled for plausibility effects by exchanging $\mathrm{N}_{\mathrm{I}}$ and $\mathrm{N}_{2}$ in half of the cases (the assistant of the lawyer rather than the lawyer of the assistant; we followed this procedure in all the experiments presented here).

[II L'avocat de l'assistant de a. Gallu / b. Galluregnoto / c. Gallu-Régnoto a discuté avec le nouveau juge.

The lawyer of the assistant from a. Gallu / b. Galluregnoto / c. Gallu-Régnoto discussed with the new judge.

[I2] Le nouveau juge a discuté avec l'avocat de l'assistant de a. Gallu / b. Galluregnoto / c. Gallu-Régnoto.

The new judge discussed with the lawyer of the assistant from a. Gallu / b. Galluregnoto / c. Gallu-Régnoto.

[13] L'assistant de l'avocat d' a. Apt / b. Albertville / c. Aix-en-Provence a discuté avec le nouveau juge.

The assistant of the lawyer from a. Apt / b. Albertville / c. Aix-en-Provence discussed with the new judge.

[I4] Le nouveau juge a discuté avec l'assistant de l'avocat d' a. Apt / b. Albertville / c. Aix-en-Provence.

The new judge discussed with the assistant of the lawyer from a. Apt / b. Albertville / c. Aix-en-Provence.

\subsection{Methods}

The three experimental factors we varied were length (short, long, composed), position (subject or object) and type of name (invented vs. real). We varied length and position as within participants factors and type of name as a between 
participants factor. All three factors were realized as within items factors. Each participant was presented with a given target sentence only once. I2 experimental lists were prepared to balance conditions across participants. Within each list, 24 experimental sentences ( 4 per condition) were randomly interspersed among 36 fillers.

24 students from the Universite de Provence at Aix-en-Provence, all native speakers of French, were presented with invented city names, 48 with real city names. They had to silently read the sentences and to indicate the preferred host for the PP in a paraphrase like [I5].

[rs] Le vient de Gallu. The comes from Gallu.

\subsection{Hypotheses}

If the IPH is correct, long PPs will be attached high and short PPs will be attached low, since modifiers tend to attach to a head of similar prosodic heaviness.

$$
\begin{aligned}
& -\mathrm{N}_{\mathrm{I}} \text {-of-N2-(short)PP }=\mathrm{N}_{2}>\mathrm{N}_{\mathrm{I}} \\
& -\mathrm{N}_{\mathrm{I}} \text {-of-N2-(long)PP }=\mathrm{N}_{1}>\mathrm{N}_{2}
\end{aligned}
$$

If the ILH account is correct, PPs will be attached low, independent of PP length, since $\mathrm{PP}$-attachment relies only on syntactic recency as long as no information is added, thus increasing processing cost.

$$
\text { - NI-of-N2-(short, long)PP = N2 > NI }
$$

\subsection{Results}

The results of all the three experiments will be presented in percentages of $\mathrm{NI}_{\mathrm{I}}$ attachment for clarity's sake in all Figures and Tables. For the statistical analyses, however, high attachments were assigned a $\mathrm{I}$ and low attachments were assigned a $\mathrm{o}$ for a log-linear mixed-effects model analysis with position, length and name type as fixed effects, participants and items as random effects (cf. Baayen et al., 2008) including slopes for position and length for subjects, and slopes for host, length, and name type for items. All data were analyzed using R (R Development Core Team, 2009) and the R packages lme4 (Bates \& Maechler, 2009) and languageR (Baayen, 2008). Fixed effects showed a highly reliable effect on the intercept, reflecting a strong preference for $\mathrm{N}_{2}$-attachment $(86.67 \% \mathrm{~N} 2$-attachments; $\beta=3.00135$; $\mathrm{SE}=0.47894 ; \mathrm{z}$-value $=6.267 ; \mathrm{p}<. .00 \mathrm{I})$. Only name type rendered a reliable fixed effect as well (name_typereal: $ß=-1.10739 ; \mathrm{SE}=0.44542 ; \mathrm{z}$-value $=-2.486 ; \mathrm{p}<.02$; all other ps $>.20$ ). This effect of name type was confirmed using likelihood ratio tests between full and reduced models $\left(\chi_{2}(\mathrm{I})=2 \mathrm{I} .148 ; \mathrm{p}<.00 \mathrm{I}\right)$, indicating that high attachment is an easier choice for real city names $\left(8.83 \% \mathrm{NI}_{\mathrm{I}}\right.$-attachments for invented names; $17.83 \% \mathrm{NI}$-attachments for real city names). No other main effect or statistical interaction turned out to be significant. 


\begin{tabular}{|l|l|l|l|}
\hline \multicolumn{4}{|l|}{ Modified subject } \\
\hline & Short & Long & Composed \\
\hline Invented name & 6 & 6 & IO \\
\hline Real name & 2I & IO & 2I \\
\hline & Modified object & II & II \\
\hline Invented name & 9 & 2I & 2I \\
\hline Real name & I3 & & \\
\hline
\end{tabular}

Table 1. Percentage of N1-attachments for short, long, and composed PP-nouns for invented and real city names

\subsection{Discussion}

If attachment preferences were based purely on numbers of syllables, increasing syllable length should have changed the attachment pattern. However, no such length effect could be established in this experiment either for invented names or for real names. These data are compatible with theories of sentence processing where PP-attachment ambiguities, which (contrary to RC-attachment ambiguities) do not involve an anaphoric component, are initially resolved only by recency (see footnote I). A possible counterargument for invented names could have been that the unknown city names in this experiment were just overlooked by the participants. Moreover, the phonology of the invented names was less French than the real city names (it was actually closer to Italian city names). Since they did not really know the cities in the experiment, they may have stopped reading them in full, with the result that differences in length no longer exerted any influence on their internal prosodic representation of the respective sentence. However, even with real city names, we were not able to obtain a significant length effect. This may indicate that adding syllables only (a pure length effect) does not necessarily result in changes in attachment preferences. Interestingly, we found a significant effect between the number of high attachments for invented vs. real city names, which did not interact, however, with length or position. Real city names were attached to Ni more often than invented names. This may be an indication that processing words with content increases $\mathrm{N}_{\mathrm{I}}$-attachments. However, to fully argue for the ILH, we do not only need to show that increasing length in terms of syllables does not lead to an increase in $\mathrm{NI}$-attachments, but also that explicitly increasing information load by adding content at the same time does.

\section{Experiment 2}

In a second questionnaire study, we therefore constructed our experimental material by adding content words as in $[\mathrm{I} 6 \mathrm{a} / \mathrm{b}]$. 
[16] Le nouveau juge a discuté avec l'assistant de l'avocat a. d'Apt / b. de la belle ville d'Apt. The new judge discussed with the assistant of the lawyer from $a$. Apt / b. the beautiful city of Apt.

\subsection{Methods}

In this experiment we only looked at the attachment of PP-modifiers in object position. In Experiment I, the position of the modified nouns did not influence attachment preferences significantly. Numerically, there were slightly more high attachments for long nouns in object position (short: II \%, long: $16 \%$, composed: I6\%). This suggests that this may be the more likely place to find length effects. The experimental techniques as well as the participants were identical to the real city condition in Experiment I.

\subsection{Results}

We analyzed the data with a log-linear mixed-effects model analysis with length as fixed effect, participants and items as random effects as well as the slopes for participant and item for the length conditions. In this experiment, beyond a general preference for $\mathrm{N}_{2}$-attachment (intercept: $\beta=2.1826 ; \mathrm{SE}=0.3053$; z-value $=7.150$; $\mathrm{p}<.00 \mathrm{I})$, a reliable $\mathrm{I} 3 \%$ increase of $\mathrm{N}_{\mathrm{I}}$-attachments was found for longer PPs as evidenced in Figure I (length: $\beta=-0.8164 ; \mathrm{SE}=0.2760 ; \mathrm{z}$-value $=-2.958 ; \mathrm{p}<. . \mathrm{oI}$ ).

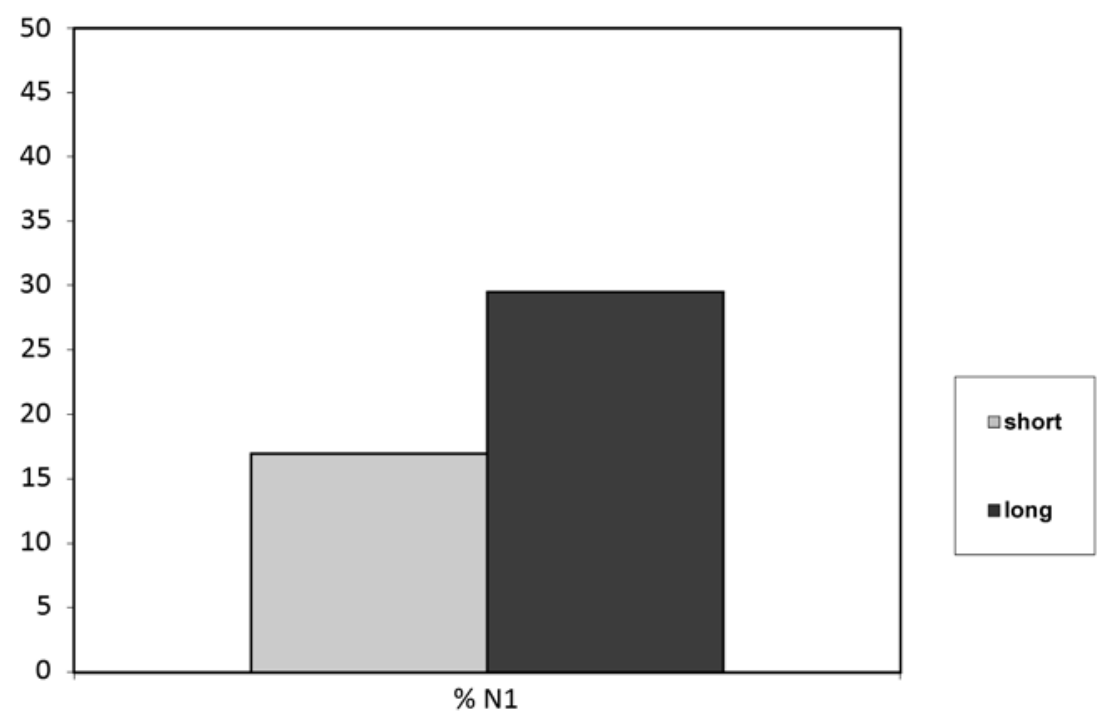

Figure 1. Adding content words, percentage of N1-attachments

\subsection{Discussion}

Adding content words apparently leads to an increase in $\mathrm{NI}$-attachments. This result already shows that the role of constituent length in syntactic ambiguity resolution 
is not limited to RCs (see also e.g., Abeillé et al., 20or; Watson \& Gibson, 2004). However, the long versions in these examples were also longer than the long versions in the earlier experiments, and this may be the reason why we found a length effect here. There may be some threshold for changes in attachment preferences such that only a considerable increase in length changes the strong base preference for $\mathrm{N}_{2}$-attachment. Unfortunately, it is grammatically not possible to lengthen the French PPs just by a single word, and at the same time real city names with more than 5 syllables are not very frequent either. We therefore decided to run a German version of the study since more controlled lengthening of the PPs is possible in German.

\section{Experiment 3}

In a third study on PP-attachment in German, we constructed materials based on the French questionnaires with a short (one-syllable) city name [I7a], a long version with a composed city name $\left[\mathrm{I}_{7} \mathrm{~b}\right]$, and a third condition, where we added an adjective $[\mathrm{I7c}]$. Here, the two long versions did not differ with respect to length in number of syllables. Following Wiese (2000), we assume that all three variants form only one phonological phrase, applying a simplified definition of phonological phrases as an NP, VP (verb phrase), or AP (adjective phrase) which is "expanded beyond the head word by some complement or modifying expression" (Wiese, 2000: 74; see also Nespor \& Vogel, 1986). Both long versions contain two lexical accents ("AU-WINterach" for the long names, "SCHOEnen AU" for the modified noun). Anttila et al. (2010) show for English that prosodic weight has its strongest impact on constituent ordering when it is measured as number of stressed syllables. The two long versions in this experiment do not differ in this respect (assuming that German is prosodically similar enough to English so that similar constraints will hold). They do however both differ from the short version, which has only one stressed syllable. Another possible difference between the composed city names and the adjective name sequences may be that the city names could possibly be considered as only prosodically branching whereas the adjective-noun sequences are syntactically as well as prosodically branching. D'Imperio et al. (2005) did however find highly similar frequencies for prosodic boundaries for two prosodic words (prosodic branching) as for syntactically branching constituents for Italian.

[17] Der neue Richter diskutierte mit dem Assistenten des Notars aus a. Au / b. AuWinterach / c. dem schoenen Au.

The new judge discussed with the assistant of the lawyer from $a . A u / b$. Au-Winterach / c. beautiful Au.

\subsection{Methods}

The experimental technique applied here was the same as in the previous experiments. We constructed 6 lists to balance conditions across participants. Each participant 
was presented with is experimental sentences (all translations of a randomly chosen set of the French materials), i.e., 5 sentences per condition interspersed among 45 filler sentences.

48 native German students from the University of Freiburg participated in this experiment.

\subsection{Results and discussion}

We ran a log-linear mixed-effects model analysis with length as fixed effect, participants and items as random effects including the slopes for participant and item for the length conditions. Again we found a strong preference for low attachment in this experiment (intercept: $B=\mathrm{I} .8097 ; \mathrm{SE}=0.3305$; $\mathrm{z}$-value $=5.476 ; \mathrm{p}<.00 \mathrm{I}$ ). Whereas fixed effects only showed a non-significant $5 \%$ increase of $\mathrm{N}_{\mathrm{I}}$-attachments for long city-names (composed: $\beta=-0.4674 ; \mathrm{SE}=0.2782 ; \mathrm{z}$-value $=-\mathrm{I} .68 \mathrm{O} ; \mathrm{p}=0.0929$ ), adding an adjective led to a significant $17 \%$ increase in $\mathrm{NI}$-attachments $(\beta=-\mathrm{I} .1957$; $\mathrm{SE}=0.289 \mathrm{o} ; \mathrm{z}$-value $=-4.138 ; \mathrm{p}<. \mathrm{OOI})$ compared to the short condition and also a significant $\mathrm{I}_{2} \%$ increase compared to the long city name $(B=0.7090$; $\mathrm{SE}=0.2490$; $\mathrm{z}$-value $=2.847 ; \mathrm{p}<. \mathrm{oI})$. Comparing the full model with a reduced model using likelihood ratio tests confirmed a significant length effect $(\chi 2(2)=\mathrm{I} 2.202 ; \mathrm{p}<. \mathrm{OI})$.

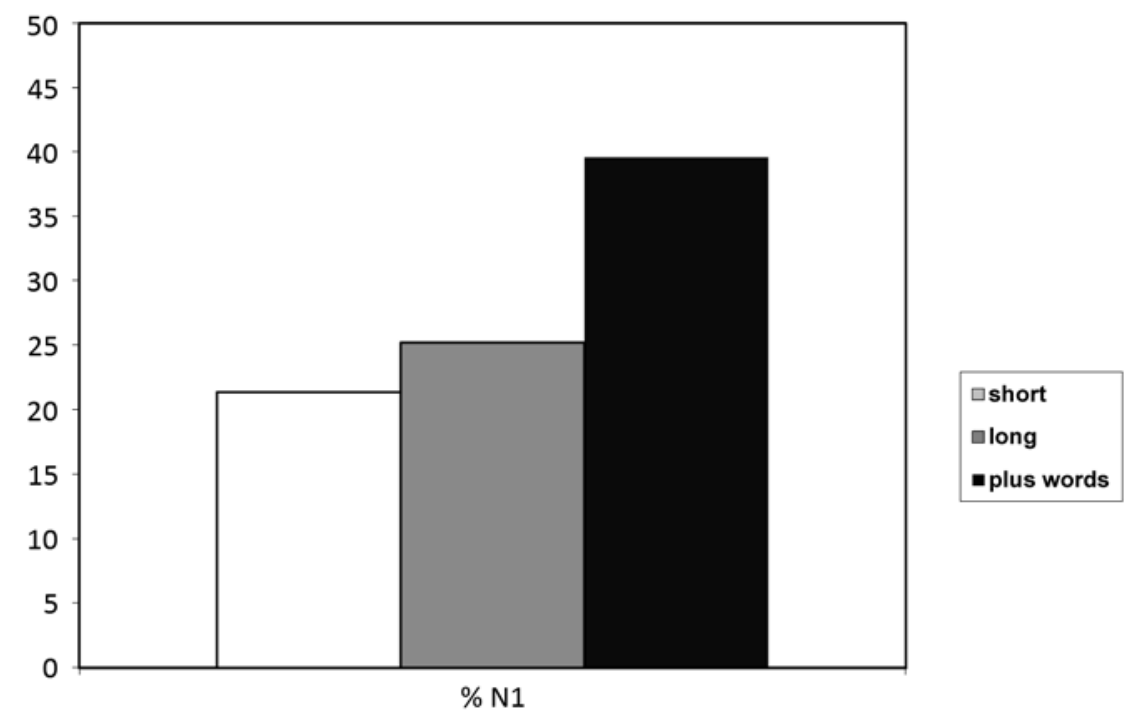

Figure 2. Length effects in German, percentage of N1-attachments for short, long composed and long modified names

The data from the German experiment are actually the most telling, because they directly compare conditions of equal length but with different pragmatic conditions. So this experiment directly shows that when length is kept constant, what changes the attachment preference is adding a content word. We are, however, aware of the 
fact that we need to be careful with generalizations in particular of prosodic weight across languages given the language-specific differences in prosody.

\section{General Discussion}

The pattern of data found in this series of experiments is highly compatible with a pragmatic interpretation of the length effect. Length alone in terms of numbers of syllables did not affect attachment decisions significantly. Increasing the informativity of the PP by adding a content word lead to an increased number of attachments to more central elements of the proposition. This evidence is moreover fully in line with recent data from reading aloud experiments in English (Breen et al., 20II) as well as corpus analyses in French (Thuilier, 2012). Breen analyzed prosodic boundaries in read aloud experiments on sentences like [18] varying in the length of the constituents. They found that the number of syllables did not correlate with boundary labels in terms of ToBI (Tones and Break Indices: Silverman et al., 1992), nor with post-word silence. The best predictor of prosodic boundaries in their data was the number of phonological phrases. Since all critical phrases in our materials consist of only one phonological phrase, no predictions can be derived from this factor.

[18] The teacher assigned the chapter (on local history) to the students (of social science) yesterday/before the first midterm exam.

For materials extracted from the French Treebank (Abeillé et al., 2003), Thuilier showed that French NP PP ordering in sentences like [19] was correlated slightly more strongly with the number of words in a constituent than with the number of syllables.

[ig] [...] donne à ses citoyens l'impression d'avoir perdu toute capacité d'initiative.

We do not claim that our data provide evidence that prosody does not play a role in silent reading. On the contrary, there is considerable evidence from a variety of languages showing that prosodic structure can play a decisive role in reading. However, we can conclude for sure that length alone is not the decisive factor for attachment preferences in our experiments. Increased informativity is a highly probable factor to be taken into account beyond prosodic structure. We do however propose that prosody plays its role as part of a more complex model (see Figure 3 and Gries [2003] for a similar line of argumentation for constituent order preferences).

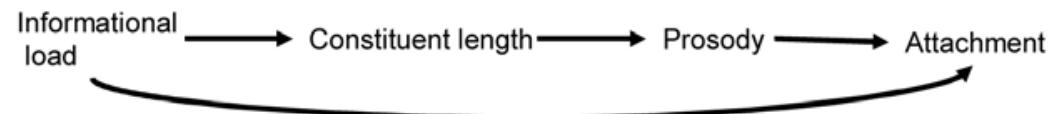

Figure 3. Direct and indirect influence of informational load 
The model we propose includes a direct as well as an indirect influence of informational load on attachment preferences (see Figure 3). The indirect influence relies on the fact that informational load influences constituent length. A preference for prosodic boundaries before long constituents (Watson \& Gibson, 2004) may then be taken as evidence for not attaching the long constituent locally. Informativity alone influences attachment as well; we therefore also assume a direct link between informational load and attachment preferences.

\section{References}

Abeillé, A., Clément, L. \& Toussenel, F. 2003. Building a Treebank for French. In A. Abeillé (ed.), Treebanks: Building and Using Parsed Corpora. Dordrecht: Kluwer Academic Publishers: 165 -187.

Abeillé, A., Pynte, J. \& Toussanel, F. 20or. Constituent Length and Attachment Preferences in French. In Proceedings of the 200I AMLaP Conference, Saarbrücken, Germany, September 20-22.

Almor, A. 1999. Noun-Phrase Anaphora and Focus: The Informational Load Hypothesis. Psychological Review 106 (4): 748-765.

Anttila, A., Adams, M. \& Speriosu, M. 20io. The Role of Prosody in the English Dative Alternation. Language and Cognitive Processes 25 (7-8-9): 946-98I.

Arnold, J.E., Wasow, T., Losongco, T. \& Ginstrom, R. 2000. Heaviness vs. Newness: The Effects of Structural Complexity and Discourse Status on Constituent Ordering. Language 76 (I): 28-55.

BaAyen, R.H. 2008. Analyzing Linguistic Data. A Practical Introduction to Statistics Using R. Cambridge: Cambridge University Press.

BaAyen, R.H., Davidson, D.J. \& Bates, D.M. 2008. Mixed-Effects Modeling with Crossed Random Effects for Subjects and Items. Journal of Memory and Language 59 (4):390-412.

Bard, E.G., Anderson, A.H., Sotillo, C., Aylett, M., Doherty-Sneddon, G. \& NewLands, A. 2000. Controlling the Intelligibility of Referring Expressions in Dialogue. Journal of Memory and Language $42(\mathrm{I}): \mathrm{I}-22$.

Bard, E.G. \& AyletT, M.P. 1999. The Dissociation of Deaccenting, Givenness, and Syntactic Role in Spontaneous Speech. In J.J. Ohala, Y. Hasegawa, D. Ohala, A. Granville \& C. BAILEy (eds.), Proceedings of the XIVth International Congress of Phonetic Sciences: ICPbS 99, San Francisco, I-7 August 1999. Berkeley: University of California: 1753-1756.

Bates, D. \& Mä̈ChleR, M. 2009. "Ime4": Linear Mixed-Effects Models Using S4 Classes. Available online: http://CRAN.R-project.org/package=lme4.

Bradley, D., Fernández, E. \& Taylor, D. 2003. Prosodic Weight versus Information Load in the Relative Clause Attachment Ambiguity. In Proceedings of the I6th Annual CUNY Conference on Human Sentence Processing, Cambridge (Mass.), MIT, March 27-29.

Breen, M., Watson, D.G. \& Gibson, E. 2oII. Intonational Phrasing is Constrained by Meaning, not Balance. Language and Cognitive Processes 26 (1о): 1532-1562.

Carlson, K., Clifton, C. Jr. \& Frazier, L. 2ooi. Prosodic Boundaries in Adjunct Attachment. Journal of Memory and Language $45(\mathrm{I}): 58-8 \mathrm{I}$. 
Clifton, C. Jr., Carlson, K. \& Frazier, L. 2002. Informative Prosodic Boundaries. Language and Speech 45 (2): 87-II4.

Clifton, C. Jr., Frazier, L. \& Carlson, K. 2006. Tracking the What and Why of Speakers' Choices: Prosodic Boundaries and the Length of Constituents. Psychonomic Bulletin and Review I3 (5): 854-86r.

Colonna, S. \& Pynte, J. 20or. The Role of Fodor's "Same-Size-Sister" Constraint in Relative Clause Attachment in French. In Proceedings of the XIIth Conference of the European Society for Cognitive Psychology, Edinburgh, September 5-8.

D’Imperio, M., Elordieta, G., Frota, S., Prieto, P. \& VigÁrio, M. 2005. Intonational Phrasing and Constituent Length in Romance. In S. Frota, M.C. Vigário \& M.J. Freitas (eds.), Prosodies: With Special Reference to Iberian Languages. Berlin - New York: Mouton de Gruyter: 59-97.

Fernández, E.M. 2003. Bilingual Sentence Processing: Relative Clause Attachment in English and Spanish. Amsterdam: J. Benjamins.

Fodor, J.D. 1998. Learning to Parse? Journal of Psycholinguistic Research 27 (2): 285-319.

Fodor, J.D. 2002. Psycholinguistics Cannot Escape Prosody. In B. Bel \& I. Marlien (eds.), Speech Prosody 2002: Proceedings, Aix-en-Provence, France, II-I3 April 2002. Aix-en-Provence: Laboratoire parole et langage - SProSIG: 83-88.

Frazier, L. 1987. Sentence Processing: A Tutorial Review. In M. Coltheart (ed.), The Psychology of Reading. Attention and Performance i2. Hove - London - Hillsdale: L. Erlbaum: 559-586.

Frazier, L. 1990. Parsing Modifiers: Special-Purpose Routines in the Human Sentence Processing Mechanism? In D.A. Balota, G.B. Flores D’Arcais \& K. Rayner (eds.), Comprehension Processes in Reading. Hove - London - Hillsdale: L. Erlbaum: 303-330.

Frazier, L. \& Clifton, C. Jr. 1996. Construal. Cambridge (Mass.) - London: MIT Press.

Frazier, L. \& Fodor, J.D. 1978. The Sausage Machine: A New Two-Stage Parsing Model. Cognition 6 (4): 29I-325.

GrIEs, S.T. 2003. Grammatical Variation in English: A Question of "Structure vs. Function"? In G. Rohdenburg \& B. Mondorf (eds.), Determinants of Grammatical Variation in English. Berlin - New York: Mouton de Gruyter: $155^{-173}$.

Hemforth, B., Fernandez, S., Clifton, C., Frazier, L. \& Konieczny, L. submitted. Relative Clause Attachment in German, English, Spanish and French: Effects of Position and Length.

Hemforth, B., Konieczny, L. \& Scheepers, C. 200oa. Syntactic Attachment and Anaphor Resolution: The Two Sides of Relative Clause Attachment. In M.W. Crocker, M. Pickering \& C. Clifton Jr. (eds.), Architectures and Mechanisms for Language Processing. Cambridge - New York: Cambridge University Press: 259-28I.

Hemforth, B., Konieczny, L. \& Scheepers, C. 20oob. Modifier Attachment: Relative Clauses and Coordinations. In B. Hemforth \& L. Konieczny (eds.), German Sentence Processing. Dordrecht - London: Kluwer Academic Publishers: I6I-I86.

Hemforth, B., Konieczny, L. \& Strube, G. I993. Incremental Syntax Processing and Parsing Strategies. In Proceedings of the Isth Annual Conference of the Cognitive Science Society: June I8 to 2I, 1993, Institute of Cognitive Science, University of Colorado, Boulder. Hillsdale: L. Erlbaum: 539-545. 
Hyams, N. \& Wexler, K. 1993. On the Grammatical Basis of Null Subjects in Child Language. Linguistic Inquiry 24 (3): 42I-459.

Konieczny, L. \& Hemforth, B. 2000. Modifier Attachment in German: Relative Clauses and Prepositional Phrases. In A. Kennedy, R. Radach, D. Heller \& J. Pynte (eds.), Reading as a Perceptual Process. Amsterdam - Oxford: Elsevier: 517-527.

Inoue, A. \& Fodor, J.D. I995. Information-Paced Parsing of Japanese. In R. MazuKa \& N. Nagai (eds.), Japanese Sentence Processing. Hillsdale: L. Erlbaum: 9-62.

Jun, S.-A. 2003. Prosodic Phrasing and Attachment Preferences. Journal of Psycholinguistic Research 32 (2): 219-249.

Levinson, S.C. 1987. Minimization and Conversational Inference. In M. BertuCCELLI-PAPI \& J. Verschueren (eds.), The Pragmatic Perspective: Selected Papers from the 1985 International Pragmatics Conference. Amsterdam: J. Benjamins: 6I-I29.

Levinson, S.C. I99I. Pragmatic Reduction of the Binding Conditions Revisited. Journal of Linguistics 27 (I): I07-16I.

LeVY, R. \& Florian, J.T. 2007. Speakers Optimize Information Density through Syntactic Reduction. In B. Schölkopf, J.C. Platt \& T. Hoffmann (eds.), Advances in Neural Information Processing Systems 19: Proceedings of the 2006 Conference. Cambridge: MIT Press: $849-856$.

Muckel Pappert, S., Schliesser, J., Pechmann, T. \& Lingel, S. 2004. Zur prosodischen Differenzierung zwischen syntaktischen Strukturen. Linguistische Arbeitsberichte 8I: 223-24I.

Nespor, M. \& Vogel, I. 1986. Prosodic Phonology. Dordrecht - Riverton: Foris Publications.

Niv, M. 1992. Right Association Revisited. In Proceedings of the 3oth Annual Meeting of the Association for Computational Linguistics. Stroudsburg: Association for Computational Linguistics: 285-287. Available online: http://aclweb.org/anthology/P/P92/P92-IO39.pdf.

Pynte, J. 2006. Phrasing Effects in Comprehending PP Constructions. Journal of Psycholinguistic Research 35 (3): 245-265.

Pynte, J. \& Colonna, S. 200o. Decoupling Syntactic Parsing from Visual Inspection: The Case of Relative Clause Attachment in French. In A. Kennedy, R. Radach, D. Heller \& J. Pynte (eds.), Reading as a Perceptual Process. Amsterdam - Oxford: Elsevier: 529-548.

Quirk, R., Greenbaum, S., Leech, G. \& Svartvik, J. 1985. A Comprehensive Grammar of the English Language. London - New York: Longman.

R Development Core Team 2009. R: A Language and Environment for Statistical Computing. Vienna: R Foundation for Statistical Computing. URL: http://www.R-project.org.

Silverman, K., Beckman, M., Pitrelli, J., Ostendorf, M., Wightman, C., Price, P., Pierrehumbert, J. \& Hirschberg, J. 1992. ToBI: A Standard for Labelling English Prosody. In ICSLP 92 Proceedings: International Conference on Spoken Language Processing, October I2-I6, I992, International Conference Centre, Banff, Alberta, Canada. Edmonton: University of Alberta. Vol. 2: 867-870.

Thornton, R., MacDonald, M.C. \& Arnold, J.E. 2000. The Concomitant Effects of Phrase Length and Informational Content in Sentence Comprehension. Journal of Psycholinguistic Research 29 (2): 195-203. 
Thuilier, J. 20I2. Contraintes préférentielles et ordre des mots en français. Unpublished $\mathrm{PhD}$ thesis. Université Paris VII-Diderot.

Watson, D. \& Gibson, E. 2004. Making Sense of the Sense Unit Condition. Linguistic Inquiry 35 (3): 508-517.

Wiese, R. 2000. The Phonology of German. Oxford: Oxford University Press.

Wijnen, F. 2004. The Implicit Prosody of Jabberwocky and the Relative Clause Attachment Riddle. In H. Quené \& V. VAn Heuven (eds.), On Speech and Language. Studies for Sieb G. Nooteboom. Utrecht: Landelijke Onderzoeksschool Taalwetenschap: 169-178. 